\title{
TWO REMARKS ON COURNOT EQUILIBRIA
}

\author{
Theodore C. BERGSTROM and Hal R. VARIAN \\ Universty of Michigan, Ann Arbor, MI 48109, USA
}

Received 30 January 1985

We describe two simple results in the theory of Cournot equilibria. The first has to do with the effect of taxation in a Cournot industry and the second describes under what conditions a Cournot equilibrium will implicitly maximize an objective function. These results are probably known, but are not well known, and they seem useful enough to be worth spelling out.

\section{Taxation in a Cournot industry}

Let $y_{i}$ be the output of firm $i, c_{i}$ its constant marginal cost. $Y$ industry output, and $P(Y)$ the industry price. Then the first-order conditions for a Cournot-Nash equilibrium can be written as

$P(Y)+P^{\prime}(Y) y_{i}-c_{i}=0$.

Summing these equations across the $n$ firms we have

$n P(Y)+P^{\prime}(Y) Y=\sum_{i=1}^{n} c_{i}$

Making the weak assumption that the left-hand side of this equation is downward sloping, there will be a unique $Y$ that solves this equation, which depends only on the sum of the marginal costs, not on their distribution across the firms. The observation that output and price in a Cournot industry is independent of the distribution of marginal costs has undoubtably been noted and used several times in the literature. See for example, Dixit and Stern (1982), Katz (1984), Loury (1983) or Bergstrom and Varian (n.d.).

Note that the same independence result holds in any conjectural variations model, as long as all firms have the same conjectural variation and we consider only interior equilibria. The latter condition becomes increasingly important as the market equilibrium approaches a competitive structure, since in that case only the low cost producer will produce a positive amount.

Here we consider an application of this result to a taxation problem. Suppose that each of the $n$ firms in the industry faces a quantity tax $t_{i}$. Then this tax is just the same as a marginal cost, so we can apply the above result to show that the equilibrium output and price is independent of the distribution of taxes across the firms. Furthermore, if we make a tax change $\left(\Delta t_{i}\right)$ that preserves the sum of the taxes, we must satisfy the first-order condition

$P(Y)+P^{\prime}(Y)\left(y_{i}+\Delta y_{i}\right)=c_{i}+t_{i}+\Delta t_{i}$, 
which implies that

$\Delta y_{i}=-\Delta t_{i} / P^{\prime}(Y)$. firm.

Thus we have an exact expression for the impact of a tax change on the equilibrium output of each

It is of interest to consider how tax revenue is affected by this sort of operation. It is most convenient to analyze this in the case of identical costs. Making this assumption, we take eq. (1), multiply through by $y_{i}$, and sum to get

$P(Y) Y-c Y+P^{\prime}(Y) \sum_{i=1}^{n} y_{i}^{2}=\sum_{i=1}^{n} t_{i} y_{i}$.

The first two terms on the left-hand side are industry profits, which we denote by $I I$. The term on the right-hand side is total tax revenue. Using the standard variance identity, we can rewrite this equation as

$R=\Pi+P^{\prime}(Y)\left[n \sigma_{y}^{2}+Y^{2} / n^{2}\right]$.

where $\sigma_{y}^{2}$ is the variance of output across firms. Using (1), we can solve for $y_{i}$,

$y_{i}=\frac{c+t_{i}-P(Y)}{P^{\prime}(Y)}$

which implies that $\sigma_{1}^{2}=\sigma_{i}^{2} / P^{\prime}(Y)^{2}$. Plugging this back into (5) we have the final result,

$R=\Pi+n \frac{\sigma_{t}^{2}}{P^{\prime}(Y)}+\frac{P^{\prime}(Y) Y^{2}}{n^{2}}$.

As we change the distribution of taxes across firms, the industry price, output and profits remain constant but tax revenue will change. The above formula shows that tax revenue is a decreasing function of the variance of the taxes across the firms in the industry. This shows for example that tax revenue is maximized when all firms face the same tax rates, as economic intuition would suggest.

\section{What does a Cournot equilibrium maximize?}

This question was first raised and answered by Spence (1976) in the context of his monopolistic competition model. It was later examined by Loury (1983) in a model of intertemporal Cournot equilibria. As far as we know this question has not been addressed for the standard Cournot model. although it may well be part of the folklore.

Let us first consider the case of identical cost functions. In what follows we will assume that $P^{\prime}(Y)<0, P^{\prime \prime}(Y)<0$, and $c^{\prime \prime}(y)>0$, although weaker assumptions will work for some of the results. In this case a symmetric Cournot equilibrium satisfies the first- and second-order conditions:

$P(Y)+P^{\prime}(Y) y-c^{\prime}(y)=0, \quad 2 P^{\prime}(Y)+P^{\prime \prime}(Y) y-c^{\prime \prime}(y)<0$.

where $y=Y / n$. Under our assumptions the second-order condition is satisfied so there is at most one symmetric Cournot equilibrium. 
Now consider the function

$F(Y)=(n-1)[U(Y)-n c(Y / n)]+P(Y) Y-n c(Y / n)$ where $\quad U(Y)=\int_{0}^{Y} P(t) \mathrm{d} t$.

That is, $U(Y)$ is just the area beneath the market demand curve - also known as consumers' surplus.

Then a local maximum of $F(Y)$ is characterized by the first- and second-order conditions.

$(n-1)\left[P(Y)-c^{\prime}(Y / n)\right]+P(Y)+P^{\prime}(Y) Y-c^{\prime}(Y / n)=0$,

$(n+1) P^{\prime}(Y)+P^{\prime \prime}(Y) Y-c^{\prime \prime}(Y / n)<0$.

Again our assumptions imply that there will be a unique maximum that satisfies these conditions. But by inspection, eqs. (8) and (10) are the same - the industry output in a symmetric Cournot equilibrium maximizes the function $F(Y)$.

It is not necessary to give the $U(Y)$ term a welfare interpretation in this context; all that matters is that its derivative is the inverse demand curve. However, the welfare interpretation is suggestive. The first term is simply the net consumers' surplus - what society should be maximizing - and the second term is profits. If there is only one firm in the market - a monopoly - industry output is determined entirely by profit maximization. As the number of firms increases, more and more weight is given to the welfare term as compared to the profit term, and as $n$ approaches infinity, industry structure approaches pure competition and thus the socially optimal level of output.

How far can we generalize this result? One interesting direction of extension would be to non-symmetric equilibria. Suppose there were some function $f\left(y_{1}, \ldots y_{n}\right)$ such that the singular points of this function were the first-order conditions that characterize a Nash equilibrium, i.e.,

$$
\frac{\partial f\left(y_{1}, \ldots, y_{n}\right)}{\partial y_{i}}=P(Y)+P^{\prime}(Y) y_{i}-c_{i}^{\prime}\left(y_{i}\right)=0 \text {. }
$$

Then applying the standard integrability conditions, we would have to have

$$
\frac{\partial^{2} f}{\partial y_{i} \partial y_{i}}=P^{\prime}(Y)+P^{\prime \prime}(Y) y_{i}=P^{\prime}(Y)+P^{\prime \prime}(Y) y_{j}=\frac{\partial^{2} f}{\partial y_{j} \partial y_{i}} \text {. }
$$

It follows that we must have $y_{i}=y_{j}=Y / n$. This observation implies that we must restrict ourselves to symmetric equilibria.

However we can relax the assumption of zero conjectural variation. If we restrict ourselves to symmetric equilibria and let $\mathrm{d} Y / \mathrm{d} y=1+\gamma$ be the conjectural variation, then it is straightforward to show that industry output maximizes the following expression:

$(n-1)[U(Y)-n c(Y / n)]+P(Y) Y-n c(Y / n)+\gamma[P(Y) Y-U(Y)]$.

This interpretation of this expression is similar to that given above, but not as natural, at least to us.

\section{References}

Bergstrom, T. and H. Varian, n.d., When are Nash equilibria independent of the distribution of agents' characteristics, Review of Economic Studies, forthcoming. 
Dixit, A. and N. Stern, 1982. Oligopoly and welfare: A unified presentation and application to trade and development. European Economic Review 19, 123-143.

Loury, G., 1983, A theory of 'oil'igopoly: Cournot equilibrium in exhaustible resource markets with fixed supplies. Harvard University working paper no. 978 (Harvard University. Cambridge. MA). Forthooming in International Economic Review. Katz, M., 1984. An analysis of cooperative research and development. Princeton University working paper 76 (Princeton University, Princeton. N.I)

Spence, M.. 1976, Product selection. fixed costs, and monopolistic competition. Review of Economic Studies 43, $217-235$. 